\title{
Skip metastasis in mediastinal lymph node is a favorable prognostic factor in N2 lung cancer patients: a meta-analysis
}

\author{
Zihuai Wang ${ }^{1,2 \#}$, Jiahan Cheng ${ }^{1,2,3,4 \#}$, Wenyu Huang ${ }^{2}$, Diou Cheng ${ }^{2}$, Yilin Liu ${ }^{2}$, Qiang Pu ${ }^{1,2}$, \\ Nathan E. Reticker-Flynn ${ }^{3,4}$, Lunxu Liu ${ }^{1,2}$ \\ ${ }^{1}$ Department of Thoracic Surgery, West China Hospital, Sichuan University, Chengdu, China; ${ }^{2}$ West China School of Medicine, Sichuan \\ University, Chengdu, China; ${ }^{3}$ Department of Pathology, School of Medicine, Stanford University, Palo Alto, CA, USA; ${ }^{4}$ Stanford Blood Center, \\ Palo Alto, CA, USA \\ Contributions: (I) Conception and design: L Liu, Z Wang (II) Administrative support: L Liu, Q Pu; (III) Provision of study materials or patients: \\ Z Wang, J Cheng, W Huang (IV) Collection and assembly of data: J Cheng, Y Liu; (V) Data analysis and interpretation: D Cheng; (VI) Manuscript \\ writing: All authors; (VII) Final approval of manuscript: All authors. \\ \#These authors contributed equally to this work. \\ Correspondence to: Lunxu Liu, MD, PhD, FRCS. No. 37, Guoxue Alley, Chengdu 610041, China. Email: lunxu_liu@aliyun.com.
}

\begin{abstract}
Background: Skip metastasis is a common lymph node metastatic pattern in non-small cell lung cancer (NSCLC). The relationship between skip metastasis and specific clinicopathologic factors and the prognostic value of skip metastasis are controversial.

Methods: A systematic search and analysis of skip metastasis in NSCLC was conducted in the databases of PubMed, EMBASE, and Web of Science up to Dec 2019. Summarized hazard ratio (HR), mean difference (MD), and odds ratio (OR) with associated $95 \%$ confidence intervals (CI) were evaluated to investigating the relationship between skip metastasis and overall survival (OS), disease-free survival (DFS), recurrence-free survival (RFS) and clinicopathological features in NSCLC.
\end{abstract}

Results: 29 studies with a total of 1,806 skip and 4,670 non-skip N2 patients were included. The upper lobe tumor showed a higher rate of skip metastasis compared with lower lobe one ( $\mathrm{RR}=1.16,95 \% \mathrm{CI}$ : $\left.1.00-1.34, \mathrm{P}=0.044, \mathrm{I}^{2}=39.8 \%\right)$. The presence of skip metastasis correlated with superior overall survival (HR $=0.74,95 \%$ CI: $\left.0.66-0.83, \mathrm{P}<0.001, \mathrm{I}^{2}=48.2 \%\right)$ and DFS or RFS (HR =0.71, 95\% CI: $0.61-0.84, \mathrm{P}<0.001$, $\left.\mathrm{I}^{2}=18.2 \%\right)$. Further subgroup analyses indicated similar results in articles that reported intrapulmonary lymph node dissection ( $\mathrm{HR}=0.67,95 \% \mathrm{CI}: 0.57-0.77, \mathrm{P}<0.001, \mathrm{I}^{2}=0$ ).

Conclusions: The results indicate that the presence of skip metastasis is associated with a marked increase in survival of NSCLC patients compared to patients with non-skip N2 metastasis. These results suggest that skip metastasis might be a distinct subgroup for purposes of N staging of NSCLC patients, and intrapulmonary lymph node assessment is needed.

Keywords: Non-small cell lung cancer (NSCLC); prognosis; skip metastasis

Submitted Aug 22, 2020. Accepted for publication Nov 17, 2020.

doi: $10.21037 /$ atm-20-3513

View this article at: http://dx.doi.org/10.21037/atm-20-3513

\section{Introduction}

Lung cancer is the leading cause of mortality among all malignancies. The 5-year overall survival (OS) rate of patients with lung cancer remains low because most cases are diagnosed in the advanced stage (1). Lymph node metastasis is one of the most important determinants of prognosis according to the TNM staging system (2). The prognosis decreases significantly when lymph node metastasis is observed, especially with the involvement of ipsilateral (N2) or contralateral (N3) mediastinal lymph nodes (3). Studies have shown that pathologic N2 NSCLC 
exhibits heterogeneous prognosis among patients (4), and those with positive mediastinal N2 lymph nodes (approximately $20-40 \%$ of all patients with NSCLC) exhibit extremely low survival rates. Nonetheless, some selected patients with $\mathrm{N} 2$ disease exhibit relatively better 5 -year survival (5). Skip metastasis in mediastinal lymph node is defined as positive N2 metastasis with the absence of N1 lymph node metastasis in hilar and intrapulmonary lymph nodes. With about $17.2-42.3 \%$ of all patients with resected pN2-NSCLC $(6,7)$, the clinical significance of skip metastasis remains unclear. According to the newest proposal for TNM staging, patients with N2 metastasis are subclassified into single-station mediastinal lymph node metastasis and multi-station metastasis $(\mathrm{N} 2 \mathrm{a}$ and N2b) (2). Single station N2 metastasis is further classified into skip metastasis and non-skip single station metastasis (N2a1 and N2a2). Many studies reported better prognosis in patients with skip metastasis compared with those with non-skip ones $(8,9)$. However, other works showed different outcomes (10). We conducted this meta-analysis to evaluate the prognostic value of skip metastasis and clinicopathologic factors that may correlate with this phenomenon. This meta-analysis was performed according to the PRISMA statement (11), and no protocol was previously published for this review.

We present the following article in accordance with the PRISMA reporting checklist (available at http://dx.doi. org/10.21037/atm-20-3513).

\section{Methods}

\section{Literature search}

A literature search was conducted in PubMed, Ovid, and Web of Science from inception through December 2019 with the following terms: ((((skip N2 OR skip mediastinal lymph node) OR skip metastases)) AND ((((lung cancer) OR lung carcinoma) OR lung neoplasm) OR lung adenocarcinomas) OR NSCLC) in all fields. All references of relevant articles were reviewed.

\section{Study selection}

The results were carefully reviewed by two authors independently (Jiahan Cheng and Zihuai Wang), and any disagreement during the process was discussed and solved with a third author (Lunxu Liu). Studies focusing on the prognostic value of skip metastasis and those reporting the relationship between clinicopathologic features and skip metastasis were included in our analysis. All the included articles assessed the pathological diagnosis under surgical resection. Reviews, conference abstracts, case reports, and in vitro or animal studies were excluded. Articles in languages other than English or Chinese were also excluded.

\section{Data extraction and quality assessment}

The full texts of all included articles were reviewed independently by two authors (Zihuai Wang and Jiahan Cheng), and the following data were extracted: publication information, study design, grouping method, sample size in each group, length of follow-up period, relevant clinicopathological characteristics, and prognostic effect of skip metastasis.

Quality assessment was conducted using the NewcastleOttawa Scale (NOS) for all included studies (12). Scores of 1-9 were assigned to articles in the categories of patient selection, group comparability and outcomes ascertainment. Articles that scored greater than 7 were deemed as high quality, those with scores of 6-7 as fair quality, and those with scores less than 6 as poor quality.

\section{Statistical analysis}

Hazard ratio (HR) and relative risk (RR) were extracted from all eligible articles along with associated $95 \%$ confidential intervals (CI). HR was employed to assess the prognostic effect of skip metastasis in overall survival (OS) and disease-free survival (DFS) or recurrence-free survival (RFS). Odds ratio (OR) was determined using MantelHaenszel method to estimate the relationship between skip metastasis and clinic-pathological characteristics. Heterogeneity among the included studies was evaluated using Chi-square test with $\mathrm{P}$ value set at 0.10 . I-square $\left(\mathrm{I}^{2}\right)$ test was applied to assess total variation among the studies. Mild heterogeneity was defined as $\mathrm{I}^{2}<50 \%$ and $\mathrm{P}>0.1$, and a standard fixed-effect model test was used to validate outcome synthesis. For studies yielding $\mathrm{P}<0.1$ or $\mathrm{I}^{2}>50 \%$, the random effect model was applied to pool the data (13). Compared with that in the fixed-effect model, weighting within the random-effect model assumes two sources of variability in effects, one from sampling error and the other from study level differences. A two-sided $\mathrm{P}$ value with $<0.05$ was viewed as statistically significant. All statistical analyses were conducted using Stata version 12.0 (StataCorp., College Station, TX, USA). 


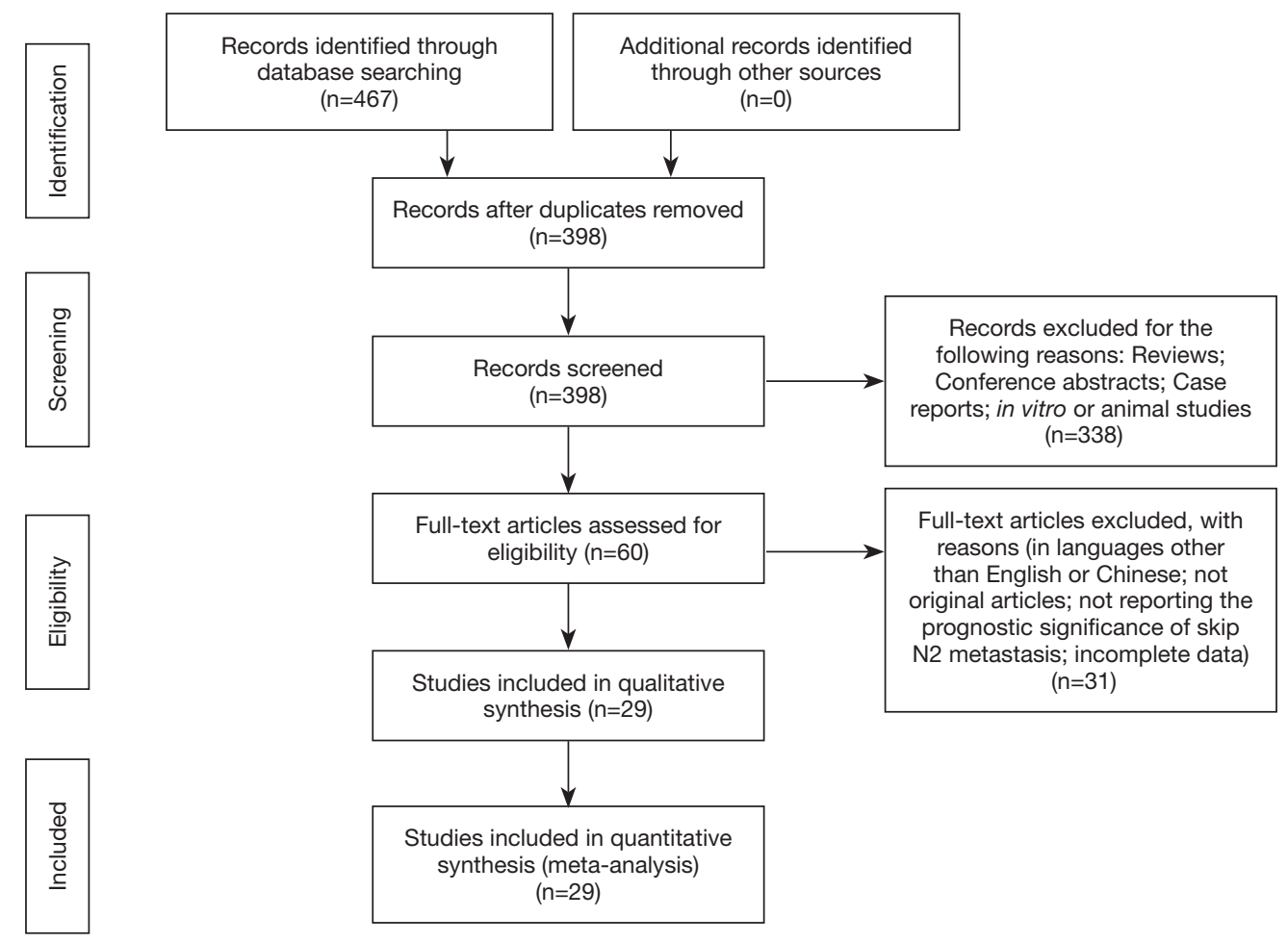

Figure 1 The flow chart of article selection.

\section{Sensitivity analysis and publication bias}

Sensitivity analysis was conducted by sequentially retracting each study to evaluate the stability of our results. Begg's weighted regression model was applied to examine the publication bias of the studies (14).

\section{Results}

\section{Article selection and quality assessment}

A total of 398 articles were found from the initial search after discarding duplicates. Following a review of titles and abstracts, the full texts of 60 papers were assessed. All reviews, conference abstracts and case reports were excluded from our analysis, yielding 29 articles for inclusion. The selection process is depicted in Figure 1. The baseline characteristics of all included articles are shown in Table 1 . The included studies were all retrospective. The articles compared the prognostic effect and clinicopathologic difference between patients with skip metastasis and nonskip N2. A total of 1,806 patients with skip N2 metastasis and 4,670 patients with $\mathrm{N} 1$ positive mediastinal metastasis were included in our study, while 3 articles did not report the exact number of the patients in each group $(2,15,16)$. The publication years spanned 1996 through 2019. Only one article underwent propensity score matching to adjust the baseline characteristics between two groups (17). Quality assessment by NOS is reported in Table 1.

\section{Prognostic effect of skip metastasis}

The association between skip metastasis and overall survival was reported in 16 studies. Skip metastasis was found to be associated with significantly better overall survival (HR $=0.74,95 \%$ CI: $\left.0.66-0.83, \mathrm{P}<0.001, \mathrm{I}^{2}=48.2 \%\right)$ compared with non-skip metastasis (Figure $2 A$ ). A subgroup analysis was conducted among articles that reported intrapulmonary lymph node dissection, and the result showed similar outcome with no heterogeneity $(\mathrm{HR}=0.67,95 \% \mathrm{CI}$ : $0.57-0.77, \mathrm{P}<0.001, \mathrm{I}^{2}=0$ ) (Figure $2 B$ ). Similar results were observed in different subgroup analysis of the favorable prognosis in skip metastatic patients (Table 2). Additionally, skip metastasis was also correlated with better disease-free survival or recurrence-free survival compared with nonskip metastasis (HR $=0.71,95 \%$ CI: $0.61-0.84, \mathrm{P}<0.001$, $\mathrm{I}^{2}=18.2 \%$ ) (Table 3). 
Table 1 Characteristics of the included studies

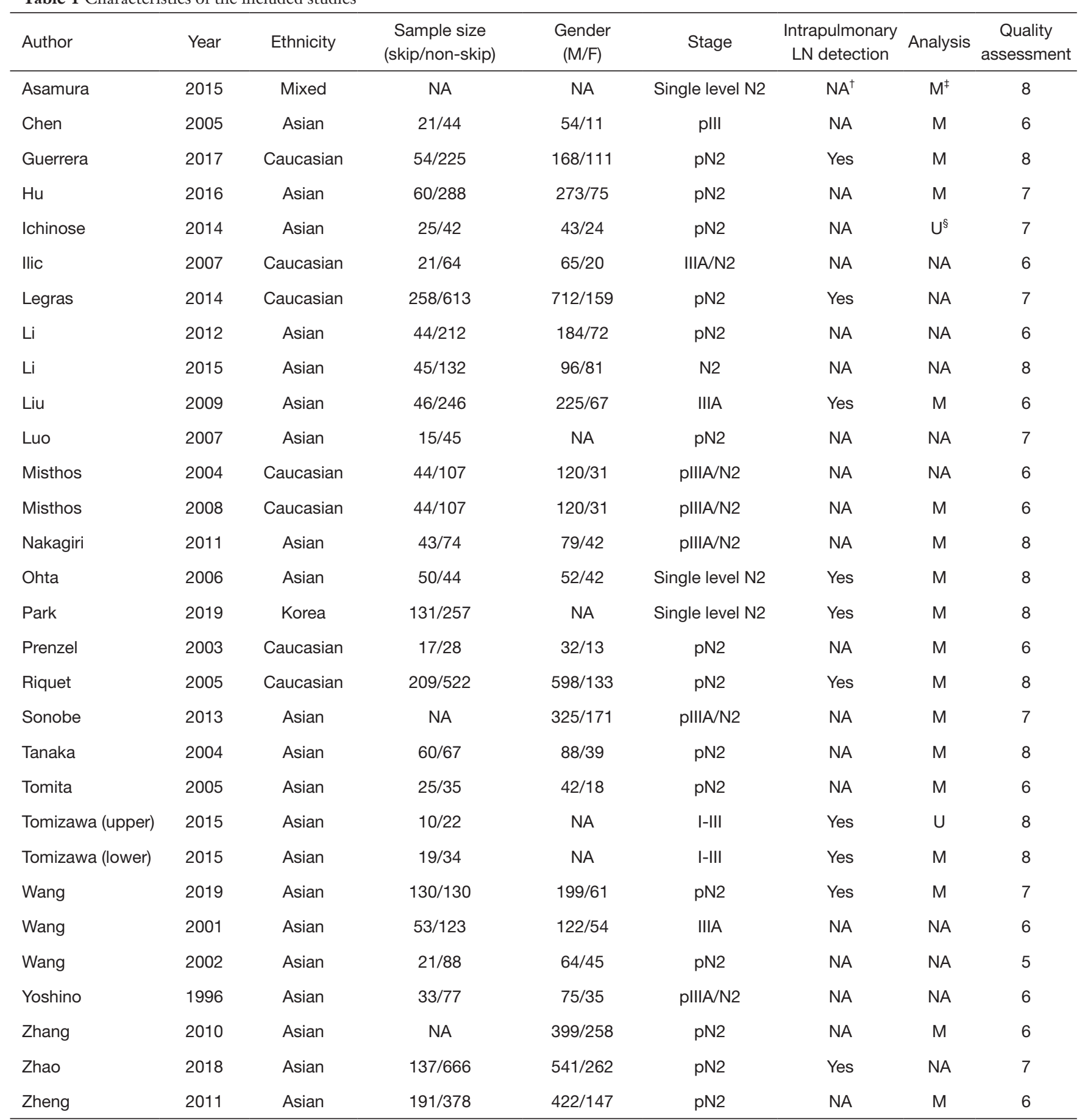

\footnotetext{
${ }^{\dagger}$, not applicable; ${ }^{\ddagger}$, multivariate analysis; ${ }^{\S}$, univariate analysis. M, male; F, female.
} 


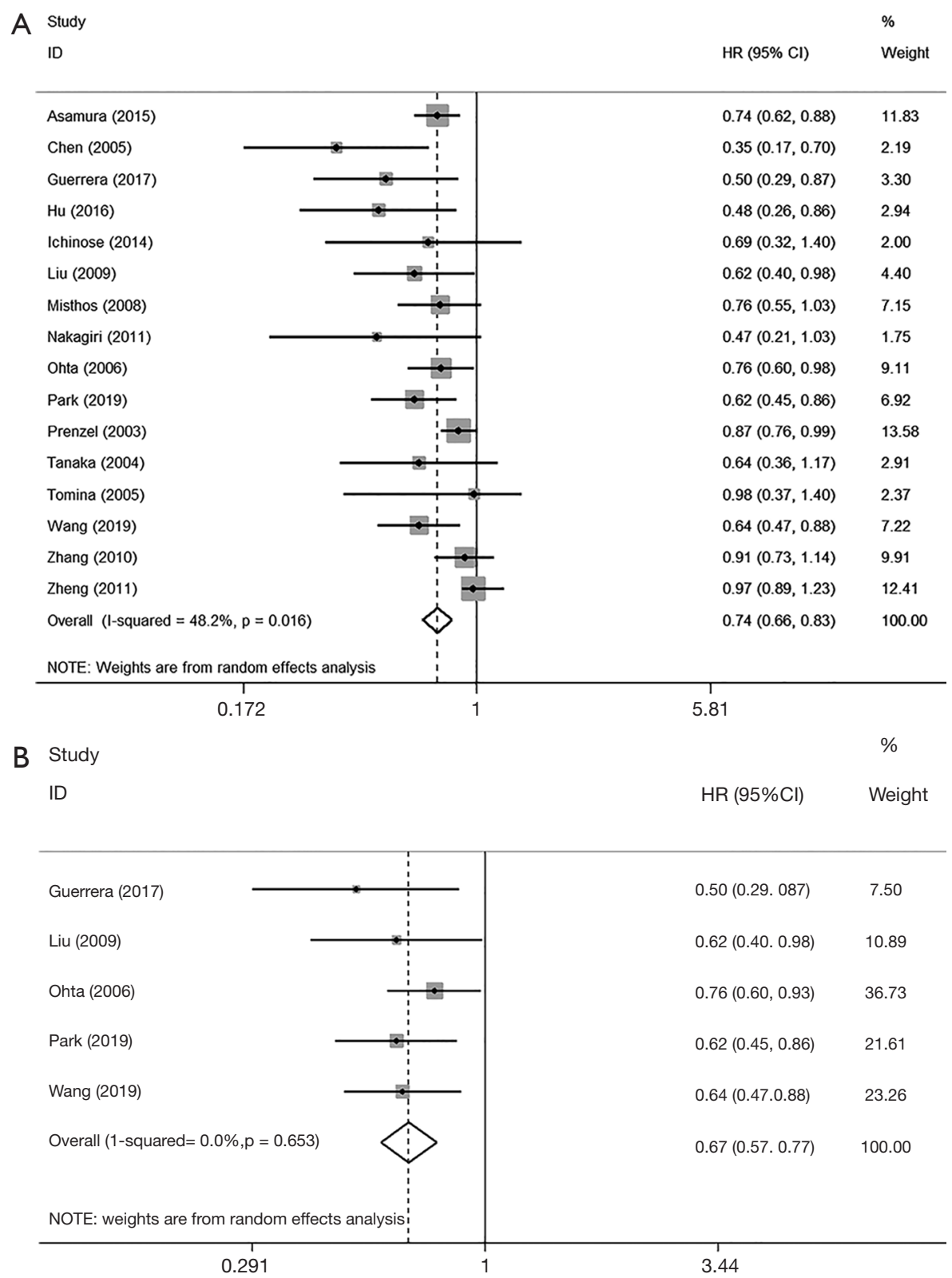

Figure 2 Comparison between skip and non-skip N2 metastatic patients in overall survival (A), and disease-free survival (B).

\section{Relationship between skip metastasis and clinicopathologic factors}

We also evaluated the correlation between clinicopathologic factors and the occurrence of skip metastasis (Table 3). Skip metastasis occurred more often in the upper lobe according to our result ( $\mathrm{RR}=1.16,95 \% \mathrm{CI}: 1.00-1.34, \mathrm{P}=0.044$, $\left.\mathrm{I}^{2}=39.8 \%\right)$. The histological subtype of NSCLC may correlate with skip metastasis in adenocarcinomas, which trended toward a lower rate of skip metastasis compared with squamous cell lung carcinoma $(\mathrm{RR}=0.85,95 \% \mathrm{CI}$ : $\left.0.70-1.04, \mathrm{P}=0.113, \mathrm{I}^{2}=0\right)$, but the result was not significant. Other factors including tumor differentiation, smoking history, pleural invasion status, and tumor diameter showed no correlation with skip metastasis (Table 3).

\section{Sensitivity analysis and publication bias}

Sensitivity analysis was conducted by omitting each study 
Table 2 Associations between clinicopathological features and skip metastasis

\begin{tabular}{|c|c|c|c|c|c|c|c|}
\hline Categories & Variables & No. of studies & \multicolumn{3}{|c|}{ Pooled data } & \multicolumn{2}{|c|}{ Heterogeneity } \\
\hline Differentiation & Well + moderate/poor & 6 & 1.06 & $0.86-1.30$ & 0.574 & 0 & 0.532 \\
\hline Histology & LUAD/LUSC & 15 & 0.85 & $0.70-1.04$ & 0.113 & 57.5 & 0.003 \\
\hline Pleural invasion & Existence/non & 3 & 0.86 & $0.67-1.10$ & 0.223 & 0 & 0.658 \\
\hline Diameter & $<3 \mathrm{~cm} />3 \mathrm{~cm}$ & 5 & 0.96 & $0.80-1.15$ & 0.645 & 48.8 & 0.099 \\
\hline Tumor location & Upper/lower & 9 & 1.16 & $1.00-1.34$ & 0.044 & 39.8 & 0.102 \\
\hline
\end{tabular}

DFS, disease free survival; RFS, recurrence free survival; LUAD, lung adenocarcinoma; LUSC, lung squamous carcinoma; HR, hazard ratio; $\mathrm{Cl}$, confidence interval; $\mathrm{Ph}, \mathrm{P}$ value for heterogeneity.

Table 3 Association between skip N2 metastasis and patient survival

\begin{tabular}{|c|c|c|c|c|}
\hline Variables & \multicolumn{4}{|c|}{ OS } \\
\hline Overall survival (skip vs. non-skip N2) & 16 & $0.74(0.66-0.83)$ & $<0.001$ & 48.20 \\
\hline \multicolumn{5}{|l|}{ By ethnicity } \\
\hline Asian & 12 & $0.71(0.61-0.84)$ & $<0.001$ & 53.6 \\
\hline \multicolumn{5}{|l|}{ By publication year } \\
\hline$\geq 2010$ & 9 & $0.72(0.61-0.85)$ & $<0.001$ & 59.1 \\
\hline$<2010$ & 7 & $0.76(0.64-0.89)$ & 0.001 & 35.7 \\
\hline \multicolumn{5}{|l|}{ By sample size } \\
\hline \multicolumn{5}{|l|}{ By lymph node map } \\
\hline Naruke & 4 & $0.78(0.61-1.00)$ & 0.051 & 58.9 \\
\hline IASLC & 4 & $0.66(0.54-0.81)$ & $<0.001$ & 0.0 \\
\hline Mixed & 1 & $0.74(0.62-0.88)$ & 0.001 & 56.9 \\
\hline Not applicable & 7 & $0.73(0.60-0.90)$ & 0.003 & 0.0 \\
\hline Disease free survival (skip vs. non-skip N2) & 3 & $0.71(0.61-0.84)$ & $<0.001$ & 18.2 \\
\hline
\end{tabular}

IASLC, International Association for the Study of Lung Cancer; ES, effect size; Cl, confidence interval.

sequentially when assessing overall survival. A consistent result was found among all studies (Figure 3). Publication bias was assessed with Begg's test and a significant publication bias was observed in overall survival with Begg's weighted regression method $(\mathrm{P}=0.034)$.

\section{Discussion}

\section{Overall description of our findings}

The existence of skip metastasis has been reported in colorectal and breast cancer with a range of $1-3 \%$ among all 


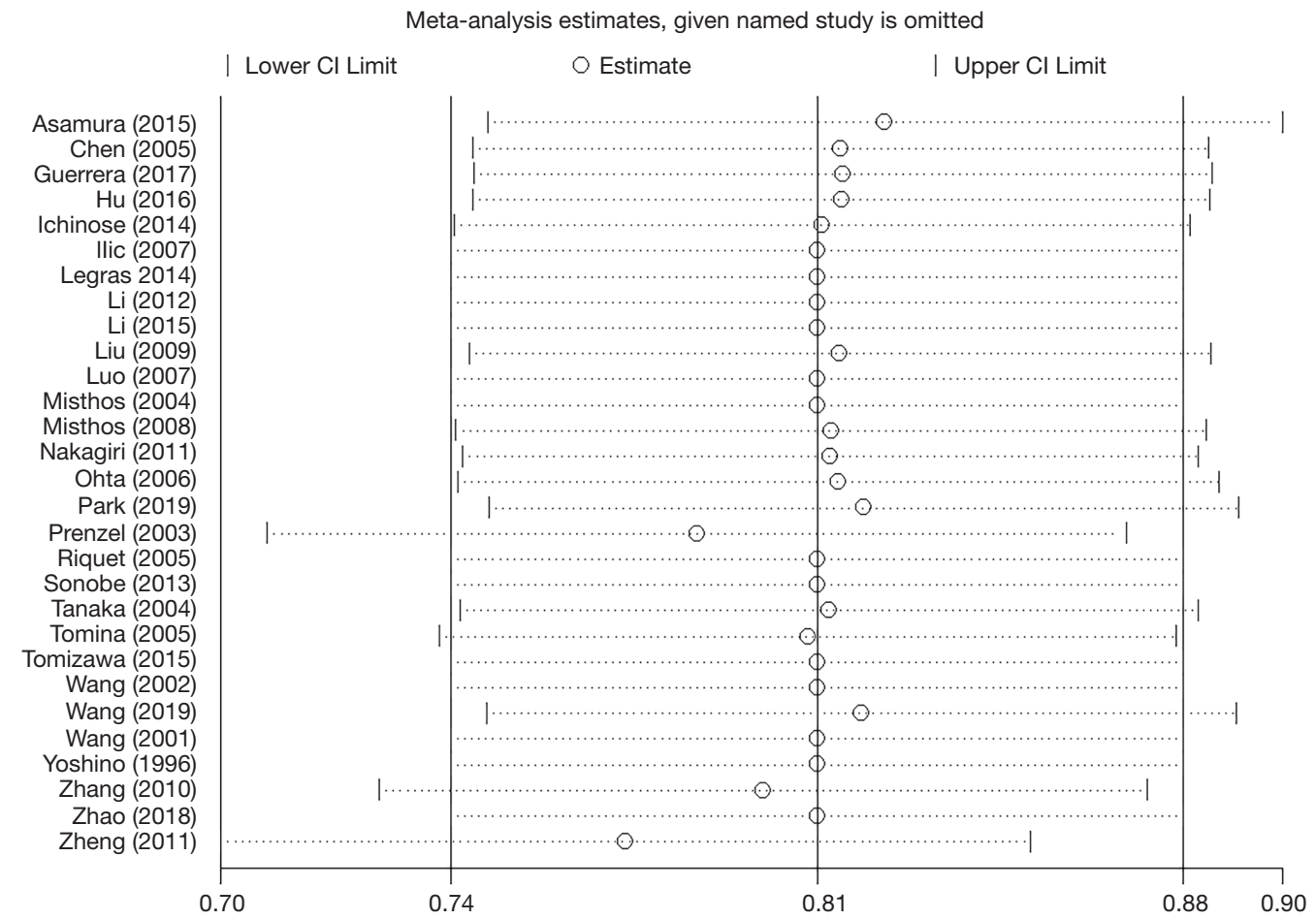

Figure 3 Sensitivity analysis in studies assessing prognostic effect of skip metastasis.

patients with lymph node metastasis $(18,19)$. The incidence of skip metastasis in patients with N2 NSCLC ranges from $20-30 \%(6,10,20)$. Although many articles reported the association between skip metastasis and improved prognosis (6), other works demonstrated different results (10). Our comprehensive analysis showed that patients with skip N2 metastasis had superior overall survival and disease-free survival compared with patients with non-skip N2.

\section{Possible mechanism of skip metastasis}

The definition of skip metastasis was further developed, representing only one station in mediastinum without the involvement of N1. Asamura and colleagues (2) observed a significantly favorable prognosis in single-station skip metastatic patients compared with non-skip single station N2 but found no significant difference between skip metastatic and multi-stational N1 metastatic groups (2). This finding was further validated in a recent study with similar results (21).

The underlying reason for skip metastasis has not been fully unveiled. One possible explanation is the different metastatic pattern in patients with skip metastasis. Previous works proved the existence of specific subpleural lymphatic drainage pathways that can directly connect to the mediastinum (22). About 23.6\% of patients with lung cancer have direct lymph node drainage pathways to the mediastinum (23). These shortcuts have higher tendency to occur in the upper lobes rather than in the lower lobes. This finding correlates with our results of the association between skip metastasis and different tumor locations (RR $=1.158, \mathrm{P}=0.044)$. The middle lobe was excluded in this subgroup analysis due to the limited patient number.

Based on evidence, a hypothesis was made that skip metastasis may have similar tumor burden as some N1 subgroup. The survival outcome among patients with multistation N1, skip N2 metastasis, and non-skip single N2 also reinforced this hypothesis $(2,21)$. In the study of Zhang et al., a different response rate was observed when using post-operative radiotherapy between patients with skip and non-skip N2 (16). This finding also indicated that a different invasive stage might exist in the two groups of patients. However, further prospective and high-level evidence is warranted in this field.

\section{Dissection of intrapulmonary lymph node}

The identification of skip metastasis requires thorough intrapulmonary lymph node dissection. Few articles 
reported the dissection of intrapulmonary lymph node, while the omission of intrapulmonary $\mathrm{N} 1$ can lead to false-positive in skip metastasis (24). In patients with N2 metastasis, the dissection of intrapulmonary lymph node is likely to be neglect because the detection of these nodes would not affect the pathologic staging. The omission of intrapulmonary lymph node may deteriorate the survival outcome in patients with "skip" metastasis and lead to a significant heterogeneity among the studies. Thus, we further analyzed the prognostic significance of skip metastasis in studies that reported intrapulmonary lymph node dissection during surgery. A subgroup analysis was conducted accordingly $(8,17,21,25,26)$. The result is consistent with no heterogeneity ( $\mathrm{HR}=0.67,95 \% \mathrm{CI}$ : 0.57 $0.77, \mathrm{P}<0.001, \mathrm{I}^{2}=0$ ), indicating that insufficient N1 lymph node dissection might indeed exist among the other studies and would lead to heterogeneous result.

In some centers, intrapulmonary nodes are detected by pathologists to define the disease lymphatic invasion status, which may lead to insufficient staging (6). To better define patients with skip N2 metastasis, surgeons should consider performing intrapulmonary node dissection to promote anatomic recognition of specimens and location of foci. Toward this goal, a standard intrapulmonary lymph node retrieval procedure would be a useful addition to the existing protocol (27).

\section{Relationship between clinicopathologic factors and skip metastasis}

Some studies compared the relationship between clinicopathologic factors and skip metastasis. Tanaka et al. reported a higher rate of skip metastasis in lung squamous carcinoma while Guerrera et al. observed a higher incidence of skip metastasis in patients with EGFR mutation $(8,28)$. A previous article concluded that tumor location, histological type and tumor size were significant factors for skip metastasis (7). No significant difference was reported in patients underwent Video assisted thoracic surgery or thoracotomy in another work (29). According to our study, lung squamous carcinoma tended toward increased skip N2 metastases compared with adenocarcinoma. Factors such as differentiation, pleural invasion, smoking status or tumor diameter were not correlated with skip metastasis in our results. The occurrence of skip metastasis was also examined. Skip occurred in stations 3 [while $3 \mathrm{~A}$ is rarely seen (30)] and 4 in right upper lobe tumor while in station 5 and 6 in left upper lobe lesion. In both lower lobe foci group, station 7 was the most frequently influenced station according to previous studies (25). The existence of metastasis in stations 4 and 7 is prevalent in patients with positive mediastinal lymph node (31). Thus, mediastinal lymph node dissection would require additional care in the above stations under the nodal station anatomy (32) even if no N1 station metastasis was found.

According to previous articles and our results, skip N2 metastasis could be a favorable prognostic indicator among patients with N2 disease. To discover the existence of skip metastasis, we recommend a thorough dissection of intra and hilar lymph nodes by trained surgeons and pathologists. The classification of $\mathrm{N}$ staging needs further development. Okada et al. proposed a different borderline between $\mathrm{N} 1$ and $\mathrm{N} 2$ in lower lobe tumors (33). Different levels of intrapulmonary lymph node metastasis were also reported to be of prognostic significance (34). However, comparison between skip and non-skip single $\mathrm{N} 2$ patients was not conducted in our work due to the scarcity of included studies. A further subdivision of patients with lymph node metastasis is needed. Furthermore, our work validated the subclassification of N2 based on the newest IASLC staging (2).

Our study presents some limitations as well. Some included articles did not report the exact number of mediastinal lymph node retrieved. According to the proposal for 8th edition of staging, patients with N2 disease are subclassified based on the number of metastatic station (2). A direct comparison between skip metastasis and multistational N1 should also be conducted in future studies. Furthermore, the publication bias among the included articles should be noticed and studies based on large-scale population should be conducted to ascertain the prognostic effect of skip metastasis.

\section{Conclusions}

Our study demonstrated a significant favorable prognostic association between skip metastasis and overall survival and disease-free survival among patients with N2 disease. Intrapulmonary lymph node retrieval should be validated more carefully. Some uncertainties regarding the significance and role of skip metastases remain unresolved, and further studies are warranted to unveil the underlying mechanism.

\section{Acknowledgments}

We want to give our sincere thanks to Prof. Edgar G. 
Engleman and KG support for the help with English language editing of the manuscript.

Funding: This work was supported by the Major Scientific and Technological Projects of the New Generation of Artificial Intelligence in Sichuan Province in 2018 under Grant 2018GZDZX0035 and the research projects of the Health Commission in Sichuan Province under Grant 20PJ054.

\section{Footnote}

Reporting Checklist: The authors have completed the PRISMA reporting checklist. Available at http://dx.doi. org/10.21037/atm-20-3513

Peer Review File: Available at http://dx.doi.org/10.21037/ atm-20-3513

Conflicts of Interest: All authors have completed the ICMJE uniform disclosure form (available at http://dx.doi. org/10.21037/atm-20-3513). The authors have no conflicts of interest to declare.

Ethical Statement: The authors are accountable for all aspects of the work in ensuring that questions related to the accuracy or integrity of any part of the work are appropriately investigated and resolved.

Open Access Statement: This is an Open Access article distributed in accordance with the Creative Commons Attribution-NonCommercial-NoDerivs 4.0 International License (CC BY-NC-ND 4.0), which permits the noncommercial replication and distribution of the article with the strict proviso that no changes or edits are made and the original work is properly cited (including links to both the formal publication through the relevant DOI and the license). See: https://creativecommons.org/licenses/by-nc-nd/4.0/.

\section{References}

1. Siegel RL, Miller KD, Jemal A. Cancer statistics, 2018. CA Cancer J Clin 2018;68:7-30.

2. Asamura H, Chansky K, Crowley J, et al. The International Association for the Study of Lung Cancer Lung Cancer Staging Project: Proposals for the Revision of the $\mathrm{N}$ Descriptors in the Forthcoming 8th Edition of the TNM Classification for Lung Cancer. J Thorac Oncol 2015;10:1675-84.
3. Kirsh MM, Kahn DR, Gago O, et al. Treatment of bronchogenic carcinoma with mediastinal metastases. Ann Thorac Surg 1971;12:11-21.

4. Sakao Y, Okumura S, Mun M, et al. Prognostic heterogeneity in multilevel $\mathrm{N} 2$ non-small cell lung cancer patients: importance of lymphadenopathy and occult intrapulmonary metastases. Ann Thorac Surg 2010;89:1060-3.

5. Libshitz HI, McKenna RJ Jr, Mountain CF. Patterns of mediastinal metastases in bronchogenic carcinoma. Chest 1986;90:229-32.

6. Riquet M, Assouad J, Bagan P, et al. Skip mediastinal lymph node metastasis and lung cancer: a particular N2 subgroup with a better prognosis. Ann Thorac Surg 2005;79:225-33.

7. Gorai A, Sakao Y, Kuroda H, et al. The clinicopathological features associated with skip N2 metastases in patients with clinical stage IA non-small-cell lung cancer. Eur J Cardiothorac Surg 2015;47:653-8.

8. Guerrera F, Renaud S, Tabbo F, et al. Epidermal growth factor receptor mutations are linked to skip N2 lymph node metastasis in resected non-small-cell lung cancer adenocarcinomas. Eur J Cardiothorac Surg 2017;51:680-8.

9. Hu XF, Duan L, Jiang GN, et al. Surgery following neoadjuvant chemotherapy for non-small-cell lung cancer patients with unexpected persistent pathological N2 disease. Mol Clin Oncol 2016;4:261-7.

10. Benoit L, Anusca A, Ortega-Deballon P, et al. Analysis of risk factors for skip lymphatic metastasis and their prognostic value in operated N2 non-small-cell lung carcinoma. Eur J Surg Oncol 2006;32:583-7.

11. Moher D, Liberati A, Tetzlaff J, et al. Preferred reporting items for systematic reviews and meta-analyses: the PRISMA statement. BMJ 2009;339:b2535.

12. Stang A. Critical evaluation of the Newcastle-Ottawa scale for the assessment of the quality of nonrandomized studies in meta-analyses. Eur J Epidemiol 2010;25:603-5.

13. Higgins JP, Thompson SG, Deeks JJ, et al. Measuring inconsistency in meta-analyses. BMJ 2003;327:557-60.

14. Begg CB, Mazumdar M. Operating characteristics of a rank correlation test for publication bias. Biometrics 1994;50:1088-101.

15. Sonobe M, Date H, Wada H, et al. Prognostic factors after complete resection of $\mathrm{pN} 2$ non-small cell lung cancer. J Thorac Cardiovasc Surg 2013;146:788-95.

16. Zhang LM, Zhang ZF, Wang CL. Clinical and prognostic analysis of skip N2 metastases in stage IIIA-N2 non-small cell lung cancer. Zhonghua Wai Ke Za Zhi 2010;48:780-3. 
17. Wang L, Zhan C, Gu J, et al. Role of Skip Mediastinal Lymph Node Metastasis for Patients With Resectable Non-small-cell Lung Cancer: A Propensity Score Matching Analysis. Clin Lung Cancer 2019;20:e346-55.

18. Rosen PP, Lesser ML, Kinne DW, et al. Discontinuous or "skip" metastases in breast carcinoma. Analysis of 1228 axillary dissections. Ann Surg 1983;197:276-83.

19. Merrie AE, Phillips LV, Yun K, et al. Skip metastases in colon cancer: assessment by lymph node mapping using molecular detection. Surgery 2001;129:684-91.

20. Isaka M, Kojima H, Takahashi S, et al. Risk factors for local recurrence after lobectomy and lymph node dissection in patients with non-small cell lung cancer: Implications for adjuvant therapy. Lung Cancer 2018;115:28-33.

21. Park BJ, Kim TH, Shin S, et al. Recommended Change in the N Descriptor Proposed by the International Association for the Study of Lung Cancer: A Validation Study. J Thorac Oncol 2019;14:1962-9.

22. Riquet M, Hidden G, Debesse B. Direct lymphatic drainage of lung segments to the mediastinal nodes. An anatomic study on 260 adults. J Thorac Cardiovasc Surg 1989;97:623-32.

23. Misthos P, Sepsas E, Kokotsakis J, et al. The significance of one-station N2 disease in the prognosis of patients with nonsmall-cell lung cancer. Ann Thorac Surg 2008;86:1626-30.

24. Wang X, Yan S, Lv C, et al. Impact of Omission of Intrapulmonary Lymph Node Retrieval on Outcome Evaluation of Lung Cancer Patients Without Lymph Node Metastasis: A Propensity Score Matching Analysis. Clinical Lung Cancer 2017;18:e411-6.

25. Liu K, Chen HL, You QS, et al. Clinical analysis of skip $\mathrm{N} 2$ metastases in stage IIIA non-small cell lung cancer. Ai Zheng 2009;28:725-9.

Cite this article as: Wang Z, Cheng J, Huang W, Cheng D, Liu Y, Pu Q, Reticker-Flynn NE, Liu L. Skip metastasis in mediastinal lymph node is a favorable prognostic factor in N2 lung cancer patients: a meta-analysis. Ann Transl Med 2021;9(3):218. doi: 10.21037/atm-20-3513
26. Ohta Y, Shimizu Y, Minato H, et al. Results of initial operations in non-small cell lung cancer patients with single-level N2 disease. Ann Thorac Surg 2006;81:427-33.

27. Osarogiagbon RU, Eke R, Sareen S, et al. The impact of a novel lung gross dissection protocol on intrapulmonary lymph node retrieval from lung cancer resection specimens. Ann Diagn Pathol 2014;18:220-6.

28. Tanaka F, Takenaka K, Oyanagi H, et al. Skip mediastinal nodal metastases in non-small cell lung cancer. Eur J Cardiothorac Surg 2004;25:1114-20.

29. Liu C, Guo C, Gan F, et al. Results of video-assisted thoracic surgery versus thoracotomy in surgical resection of pN2 non-small cell lung cancer in a Chinese highvolume Center. Surg Endosc 2020. [Epub ahead of print]. doi: 10.1007/s00464-020-07624-2.

30. Liu C, Wei S, Guo C, et al. Clinical Significance of Station 3A Lymph Node Dissection in Patients with Right-Side Non-Small-Cell Lung Cancer: A Retrospective Propensity-Matched Analysis. Ann Surg Oncol 2021;28:194-202.

31. Bille A, Woo KM, Ahmad U, et al. Incidence of occult pN2 disease following resection and mediastinal lymph node dissection in clinical stage I lung cancer patients. Eur J Cardiothorac Surg 2017;51:674-9.

32. Mountain CF, Dresler CM. Regional lymph node classification for lung cancer staging. Chest 1997;111:1718-23.

33. Okada M, Sakamoto T, Yuki T, et al. Border between N1 and N2 stations in lung carcinoma: lessons from lymph node metastatic patterns of lower lobe tumors. J Thorac Cardiovasc Surg 2005;129:825-30.

34. Shin S, Kim HK, Choi YS, et al. Prognosis of unexpected and expected pathologic N1 non-small cell lung cancer. Ann Thorac Surg 2013;96:969-75; discussion 75-6. 